\title{
MODEL SUPERVISI YANG MEMBELAJARKAN BAGI KONSELOR SEKOLAH DAN PROFESI SEJENIS
}

\author{
AgusTaufiq \\ Universitas Pendidikan Indonesia \\ afiq@upi.edu
}

\begin{abstract}
This article aims to explain the Model of Supervision of Development-Education (MSPK) as a result of literature study in research on Development of Supervision Model to Improve School Counselor Professional Performance (2010). This model has empirically been proven effective in improving the professional performance of school counselors and is assumed to be applied effectively in supervising professionals in other areas of assistance Other explanations include the MSPK framework and action steps, the theoretical foundations of learning and in supervision and the role and qualifications of supervisors.
\end{abstract}

Keywords: Supervision of development-education, Experiential-Learning, Reflection, Professional Learning

\section{A. PENDAHULUAN}

Perkembangan teknologi dan perubahan dunia profesi dalam bidang pendidikan sering merupakan hasil dari persoalan kemampuan untuk menyesuaikan diri dengan perubahan yang cepat, untuk belajar tentang berbagai hal baru. Dalam konteks ini, proses supervisi dapat dipandang sebagai salah satu dari kemungkinan proses pembelajaran profesional sepanjang hayat (life-long professional learning) dan sekaligus sebagai proses pendewasaan atau pengembangan kualtitas pribadi.

Dalam konteks life long professional learning, supervisi dipahami sebagai pembelajaran spesifik, dimana melalui refleksi pengalaman profesional yang bersifat suportif dan developmental disertai dengan konseling yang berorientasi dukungan (supportive counseling) memungkinkan para pekerja profesional yang diseupervisi, seperti konselor sekolah, para guru dan sejenisnya memperoleh wawasan (insight) profesional dan personal yang baru dari pengalaman mereka sendiri. Pola ini dimaksudkan membantu yang disupervisi untuk mengintegrasikan pengalaman praktis dengan pengetahuan teoritis, menemukan solusi sendiri atas permasalahan yang mereka hadapi di tempat kerja, menghadapi tekanan internal dan eksternal agar tetap kuat dan untuk membangun identitas profesional mereka. Dengan pola pemikiran seperti ini, supervisi benar-benar dapat mendukung pembelajaran profesional dan sekaligus pengembangan kualitas pribadi yang disupervisi.

Tulisan ini bertujuan untuk menjelasakan suatu Model Supervisi Perkembangan-Kependidikan (MSPK) yang berorientasi pada pembelajaran profesional sepanjang hayat, sehingga diasumsikan dapat memampukan konselor, bahkan profesional lainnya di sekolah seperti guru dan kepala sekolah untuk menyesuaikan diri dengan perubahan yang cepat dan aktif belajar berbagai hal baru terkait dengan tugas profesionalnya. Penjelasan meliputi kerangka pikir dan langkah kerja MSPK, landasan teoretik tentang belajar profesional dalam supervisi serta peran dan kualifikasi supervisor.

\section{B. KAJIAN LITERATUR}


1. Model Supervisi Yang Membelajarkan bagi Konselor sekolah dan Profesi sejenis

Perkembangan teknologi dan perubahan dunia profesi dalam bidang pendidikan sering merupakan hasil dari persoalan kemampuan untuk menyesuaikan diri dengan perubahan yang cepat, untuk belajar tentang berbagai hal baru. Dalam konteks ini, proses supervisi dapat dipandang sebagai salah satu dari kemungkinan proses pembelajaran profesional sepanjang hayat (life-long professional learning) dan sekaligus sebagai proses pendewasaan atau pengembangan kualtitas pribadi.

Dalam konteks life long professional learning, supervisi dipahami sebagai pembelajaran spesifik, dimana melalui refleksi pengalaman profesional yang bersifat suportif dan developmental disertai dengan konseling yang berorientasi dukungan (supportive counseling) memungkinkan para pekerja profesional yang disupervisi, seperti konselor sekolah, para guru dan sejenisnya memperoleh wawasan (insight) profesional dan personal yang baru dari pengalaman mereka sendiri. Pola ini dimaksudkan membantu yang disupervisi untuk mengintegrasikan pengalaman praktis dengan pengetahuan teoritis, menemukan solusi sendiri atas permasalahan yang mereka hadapi di tempat kerja, menghadapi tekanan internal dan eksternal agar tetap kuat dan untuk membangun identitas profesional mereka. Dengan pola pemikiran seperti ini, supervisi benarbenar dapat mendukung pembelajaran profesional dan sekaligus pengembangan kualitas pribadi yang disupervisi.

Tulisan ini bertujuan untuk menjelasakan suatu Model Supervisi Perkembangan-Kependidikan (MSPK) yang berorientasi pada pembelajaran profesional sepanjang hayat, sehingga diasumsikan dapat memampukan konselor, bahkan profesional lainnya di sekolah seperti guru dan kepala sekolah untuk menyesuaikan diri dengan perubahan yang cepat dan aktif belajar berbagai hal baru terkait dengan tugas profesionalnya. Penjelasan meliputi kerangka pikir dan langkah kerja MSPK, landasan teoretik tentang belajar profesional dalam supervisi serta peran dan kualifikasi supervisor.

2. Kerangka Pikir dan Langkah Kerja MSPK

MSPK atau DevelopmentalEducational Supervision Model, dikembangkan melalui riset ZÏ orga, (1994; 1997) dan Kobolt \& ZÏ orga, (1999). Model ini menekankan dua unsur penting, yaitu supervisi sebagai proses belajar dari pengalaman praktik profesional dan peran refleksi di dalamnya. Model ini ditandai dengan adanya komponen supervisi yang suportif, developmental dan educational dimana supervisi harus dipahami sebagai monitoring pribadi dan dorongan bagi perkembangan keprofesionalan mereka. Sasaran supervisi model MSPK utamanya adalah untuk mengintegrasikan pengalaman praktis dengan pengetahuan teoritis, menemukan solusi sendiri atas permasalahan yang mereka hadapi di tempat kerja, menghadapi tekanan internal dan eksternal agar tetap kuat dan untuk membangun identitas profesional pihak yang dispervisi. Di dalam model MSPK, para profesional dan para supervisor harus tidak saling tergantung dan mereka tidak harus terlibat di dalam hubungan yang bersifat hirarkis, seperti hubungan antara manajer dengan bawahan.

Dalam implementasi MSPK yang telah dilakukan oleh Taufiq A. $\mathrm{dkk}, 2015$, konselor difasilitasi untuk merefleksikan pengalaman kerja tertentu, penyebab dan lingkungan 
sekitar yang menimbulkan pengalaman kerja tertentu. Konselor mengungkapkan apa yang ditemukan dan upaya mencapainya, mengapa dia bertindak dengan cara tertentu atau apa yang telah memengaruhi keputusannya. Apa konsekuensi dari tindakan itu pada dirinya, pada klien, keluarganya atau pada rekan kerjanya? Dia juga mengungkapkan perasaan apa yang sudah dialami di tempat kerja, seperti halnya bagaimana perasaan klien atau mitra kerjanya. Di dalam proses refleksi itu konselor bisa merenungkan pengalamannya dari jauh. Dengan begitu dia dapat mengalami latar belakang dari tindakannya dan motivasi apa yang berulang-ulang menggiringinya pola perilaku bantuan yang mungkin tidak disukainya, atau tidak adekuat secara secara profesional.

Jika supervisi diharapkan untuk benar-benar efektif, maka supervisi harus merupakan proses yang berkelanjutan, berlangsung secara teratur dan berlangsung dalam waktu yang cukup lama. Siklus supervisi sekitar 7 10 sesi (kecuali jika ada aturan tertentu yang telah dibuat) sebab tujuannya adalah untuk menyediakan pengalaman belajar profesional dan pengembangan kualitas pribadi secara terintrgrasi. Proses supervise dapat dibagi menjadi tiga fase. Fase permulaan berlangsung 1 - 2 sesi pertemuan, di mana fokusnya terutama sekali diarahkan untuk membentuk relasi dan kontrak supervisi serta membuat suatu rencana kerja supervisi. Fase pertama itu diikuti oleh fase inti yang berlangsung antara 5-6 sesi pertemuan dimana pengalaman kerja spesifik ditangani lebih intensif dengan menggunakan mekanisme experiensial learning. Fase final terdiri dari dua atau tiga sesi pertemuan, dimana partisipan menyelesaikan persoalan yang tidak selesai, membuat evaluasi final, mengidentifikasi langkah belajar selanjutnya dan satu sama lain menyatakan selamat jumpa lagi.
Supervisi dapat diselenggarakan secara individual atau kelompok. Ukuran yang optimal suatu kelompok adalah masing-masing anggota dapat belajar secara intensional, yaitu antara empat sampai enam anggota. Supervisi individual, durasi waktu untuk satu sesi pada umumnya antara $1-1,5$ jam, sedang untuk supervisi kelompok diperlukan waktu 2-3 jam. Sekalipun cakupan kelompok itu amat luas dengan berbagai kemungkinan yang berbeda, tetapi pada umumnya kita tidak bisa membentuk suatu kelompok yang dapat memenuhi semua kondisi dengan optimal, oleh sebab itu kita harus sadar akan perangkap yang mungkin muncul pada setiap kelompok.

Struktur dari pertemuan supervisi seperti itu disebut oleh Atherton, (1986:186) dengan "mengisi sandwich" dimana lapisan pertam adalah pembukaan (pertemuan masih rahasia, persetujuan tentang struktur yang diinginkan tentang keseluruhan sesi, refleksi tentang sesi sebelumnya), lapisan yang kedua adalah penutup (kesempatan untuk mengatakan sesuatu kepada anggota yang tidak berkata sepanjang pertemuan, analisis singkat tentang pertemuan, umpan balik untuk satu sama lain, dll.) dan pengisian seperti ini adalah pekerjaan konkret pada materi supervisi, yaitu pengalaman profesional.

Dengan merefleksikan pengalaman konkret, konselor menyadari pertahanan dirinya, isi emosional dan gaya perilakunya sendiri (Abbott, A. A., \& Lyter, S. C., 1999; Bernard, J. M., \& Goodyear, R. K., 2014; Cobia, D. C., \& Boes, S. R., 2000; Ellis, M. V., 2010). Dengan kata lain konselor dapat mengenali teori implisit yang ada di dalam dirinya yang melandasi sikap dan 
nilai nilai yang mengarahkan tindakan dan respon emosionalnya, seperti halnya menggambarkan kerangka acuan yang dipakai untuk memaknai perilaku dan peristiwa tertentu yang dialami kliennya. Di dalam proses supervisi, konselor menyatakan bahwa dia menemukan makna yang benar tentang suatu peristiwa tertentu menurut dirinya secara pribadi dan bagaimana itu memengaruhi tindakan profesionalnya.

Sekali kita sudah mengenali arti dari suatu pengalaman atau suatu peristiwa, kita akan sering menemukan suatu kenyataan bahwa hal itu sebenarnya merupakan suatu pengalaman dari beberapa generasi, yang telah direkam oleh sejumlah dokumen profesional. Dalam supervisi, pihak yang disupervisi mendapatkan pencerahan seperti itu melalui melalui refleksinya (Skovholt, T.M., \& Rønnestad, M.H., 1992; Sutton, L., Townend, M., \& Wright, J., 2007).

Seketika pengalaman dan maknanya telah terintegrasi, maka akan menjadi kebijaksanaan atau wisdom. Kebijaksanaan ini tidaklah statis secara alami sebab sedang dalam proses pengintegrasian dimana kita secara konstan harus meninjau ulang dan mensort pengetahuan kita, yang mentransformasi struktur kognitif kita (Shulman, L. S., 2004; Blount, A. J., \& Mullen, P. R., 2015). Dengan cara ini pengetahuan teoritis baru dan kognisi baru, yang diperoleh melalui refleksi pengalaman dalam proses supervisi profesional menjadi terintegrasi dengan skema perilaku dan persepsi sebelumnya, mengembang ke dalam pola fungsi dan hukum profesional yang baru dan berbeda (Thwaites, R. \& Bennett-Levy, J., 2007; Laireiter, A., \& Willutzki, W., 2003).

Di dalam implementasi MSPK itu, proses belajar profesional seperti itu bagi konselor memiliki arti yang sangat esensial. Sesungguhnya, tujuan supervisi adalah untuk melibatkan pihak yang disupervisi dalam suatu proses belajar, membantu mereka untuk mengintegrasikan apa yang sedang mereka lakukan; pemikiran dan perasaannya. Dengan demikian konselor yang disupervisi dapat menghubungkan pengalaman praktis dengan pengetahuan teoritis, menggabungkan pekerjaan dengan studi, memungkinkan tranfer teori ke dalam praktek dan mendorong pembelajaran profesional secara otonom. Dengan cara seperti ini, maka supervisi akan memberi kontribusi terhadap perkembangan profesional dan personal konselor. Artinya di dalam supervisi, bekerja, pendidikan dan pengembangan pribadi harus disambungkkan melalui proses experiential learning.

\section{Landasan Teoretik MSPK}

Proses supervisi yang efektif bagi para profesional dalam bidang pendidikan difokuskan pada proses belajar dari pengalaman (experiential learning). Kolb (1984), pendiri experiential learning, mendefinisikan belajar sebagai proses dimana pengetahuan diciptakan melalui tranformasi pengalaman. Elemen dasarnya adalah pengalaman dan tranformasi. Persepsi pengalaman tidak mencukupi untuk belajar sesuatu, mesti disertai dengan tindakan nyata, atau harus ada yang dilakukan. Penggunaan pengalaman di dalam proses supervisi menurut model belajar dari Kolb adalah sebagai proses cyclical dimana empat aktivitas saling berinteraksi: pengalaman konkret (concrete experience), refleksi (its reflection), konseptualisasi abstrak (its abstract conceptualization) dan eksperimentasi (experimentation).

Kolb (1984) menekankan bahwa proses belajar dapat dimulai dari titik manapun dari lingkaran ini, tetapi harus melewati keempat tahapan itu. 
Oleh karena itu, di dalam supervisi, proses belajar harus secara khas dimulai dengan pengalaman praktek yang dialami oleh supervisi dalam penyelenggaraan tugasnya. Selanjutnya berproses sepanjang keempat aktivitas dengan cara sebagai berikut:

a. Pengalaman konkret: di dalam supervisi hal ini mengacu pada tanggung jawab akan pengalaman kerja konret, dimana peristiwa diuraikan secara hati-hati (materi supervisi);

b. Refleksi pengalaman atau pemikiran tentang pengalaman: menyadari, menganalisis dan merefleksikan faktor-faktor yang mempengaruhi pengalaman dan peran individu di dalamnya;

c. Konseptualisasi abstrak atau pencarian arti pengalaman: membandingkan dan mencari-cari koneksi yang mungkin antara pengalaman yang direfleksikan dan pengalaman lain di masa lalu (baik yang dimiliki atau pengalaman koleganya), mengaitkan hal ini dengan pengetahuan teoritis, sikapsikap, dll;

d. Eksperimentasi praktis atau melakukannya di dalam suatu cara yang berbeda: perencanaan pola-pola tingkah laku baru dan strategistrategi serta mengujinya dalam praktek.

Seperti Piaget, Merriam \& Clark juga mengakui bahwa beberapa pengalaman hidup sehari-hari dapat dengan mudah berasimilasi ke dalam struktur mental kita sebab pengalaman itu cocok dengan pengalaman sebelumnya. Namun demikian, ada beberapa pengalaman hidup yang tidak sesuai dengan pengalaman seseorang di masa lampau dan tidak bisa ditafsirkan secara baik dengan struktur mental yang telah ada (Merriam\&Clark, 1992:3).

Sekali 'tingkat tertinggi' profesional telah dicapai, yang menurut Amerikaner, M., \& Rose, T. (2012) pada umumnya terjadi di sekitar usia tiga puluh atau empat puluh, bisa jadi diikuti oleh kebosanan yang berlangsung lama di tempat pekerjaan, yang dapat mengakibatkan perasaan mandeg (stagnancy) dalam profesi, disertai oleh sindrom kejenuhan. Oleh karena itu di dalam periode ini, penting bahwa para profesional harus mampu memproses pengalaman kerja mereka, belajar dari pengalamannya, dan mengintegrasikan kembali apa yang telah dipelajari di dalam proses supervisi.

Watkins (1995) menjelaskan bahwa pengalaman itu sendiri tidak menjamin pengembangan, walaupun kita sering berasumsi bahwa semakin berpengalaman kita akan semakin berkembang di dalam area kinerja yang lain. Karakteristik kunci, yang membedakan orang yang belajar dan tumbuh dari yang lainnya adalah self-criticism. Self-criticism harus dipahami sebagai suatu pendirian individu yang bersifat konstruktif dan evaluasional, siapa yang secara teratur menggunakan banyak waktu untuk merefleksikan apa yang sedang dilakukan berarti secara permanen dia tengah mendidik dirinya sendiri secara profesional. Singkatnya, seorang profesional adalah mereka yang aktif dan progresif bekerja meningkatkan pemahaman dan ketrampilan profesional dirinya sendiri. Hanya pengalaman yang dikombinasikan dengan cara seperti itulah selfcriticism dapat membawa atau menyempurnakan perkembangan.

Dalam kaitan ini, Lerner, R.M., (1998) memperkenalkan konsep pengembangan diri, suatu pendekatan yang menekankan pentingnya life-long learning. Pendekatan seperti itu mempertimbangkan potensi-potensi belajar kita yang besar dan potensi untuk mengubah apa yang sedang 
kita lakukan. Dia percaya bahwa pengembangan diri telah menjadi pendekatan yang sukses dan populer karena telah dapat membantu masyarakat untuk menyesuaikan diri dengan tantangan baru kehidupan organisasi untuk menikmatinya. Fokus pendekatan itu adalah siklus proses experiential learning sebagaimana dipahami oleh Kolb dengan jargon "do sometihing, think about it, make sense of it, do it differently", dan membantu pengembangan kemampuan mengambil tanggung jawab dan untuk melakukan jenis pekerjaan yang terarah pada tindakan, yaitu pekerjaan yang memberi dorongan dan tidak hanya mengarahkan cara bereaksi terhadap tantangan (Laireiter, A., \& Willutzki, W., 2003). Supervisi tentu saja perlu dipahami sebagai salah satu metode pengembangan diri seperti itu, yang dapat memberi kontribusi terhadap continuing learning dan terhadap pengembangan profesional dengan sukses.

\section{METODOLOGI PENELITIAN}

Kajian ini merupakan merpakan sebuah apanalisis tentang perkembangan keilmuan tentang peran konselor sebagai profesi professional dalam praktek pendidikan dan Pembelajaran. Analisis dilakukan terhadap trend perkembangan dan tuntutan layanan Supervisi yang ditujukan untuk membelajarkan para konselor.

\section{HASIL DAN PEMBAHASAN}

Peran supervisor adalah benar-benar untuk memandu para pekerja di dalam siklus belajar itu, melalui keempat aktivitas atau tahap proses belajar yang telah uraikan di atas. Supervisor menciptakan situasi belajar seperti itu yang mendorong para pekerja untuk transit dari fase satu ke fase yang lain. Oleh karena itu, pertemuanpertemuan supervisi perlu berlangsung paralel dengan bekerja, sehingga proses belajar terjadi dalam bentuk suatu spiral yang selalu mencapai tingkatan yang lebih tinggi. Para pekerja profesional melakukan pekerjaannya, pada pertemuan supervisi mereka merefleksikan apa yang sudah mereka lakukan dan apa yang telah mereka pelajari dari peristiwa praktek itu, kemudian mereka kembali ke pekerjaannya dan menguji apa yang telah mereka pelajari. Peran supervisor adalah menawarkan peluang kepada mereka untuk mengadakan percobaan yang aman dan menguji-coba perilaku dan cara baru. Supervisor melindungi mereka agar tidak memasuki situasi yang dapat membahayakan mereka. Itulah mengapa pengawas berdiskusi dengan mereka tentang kemungkinan pemecahan serta konsekuensinya bagi mereka. Tetapi solusi yang diputuskan oleh para pekerja profesional dan apa konsekuensi mereka belajar dari situasi yang diawasi adalah tanggung jawab mereka sendiri (Lawson, G., Hein,S.F., \& Stuart,C.L., 2009).

Peran supervisor berbeda dengan peran seorang mentor. Seorang mentor dilibatkan terutama semata di dalam penginstruksian, menasehati, monitoring, memandu dan mengevaluasi para pelajar atau rekan kerja muda pada awal karirnya. Walaupun hal ini mungkin merupakan fungsi supervisi juga (Holloway, 1995), fokus utama seorang supervisor adalah pada konseling, pendidikan dan pendukungan profesional. Supervisor menyediakan kondisi-kondisi belajar dan memandu supervisi melalui prosesproses belajar itu. Itulah mengapa supervisor pada dasarnya harus ahli dalam supervisi, sementara mentor harus ahli di dalam profesi yang sama seperti siswa dalam situasi mentoring. Mentoring adalah suatu cara untuk memasuki profesi, sedangkan supervisi digunakan oleh para profesional yang berpengalaman yang ingin meningkatkan mutu layanan profesional mereka. Kadushin (1976:129) menekankan bahwa melalui supervisi, para tenaga profesional 
dibantu untuk dapat menginternalisasikan seperangkat prinsip, sikap dan nilai-nilai yang bagian demi bagian akan mengatur perilaku masa depan mereka. Hal ini akan memampukan mereka untuk bertindak lebih otonom dan independen, sebab supervisi menyediakan para supervisi untuk memiliki pengertian akan identitas jabatan (sense of occupationalidentity).

Dengan bantuan konsep perkembangan "proximal zone," Vygotsky (1977) menguraikan bagaimana belajar berpengaruh terhadap keadaan perkembangan. Ia mendefinisikan zona perkembangan proximal sebagai jarak antara perkembangan yang nyata dan pengembangan yang potensial. Level potensi perkembangan jelasnya merupakan tugas dan permasalahan mental dimana individu dapat memecahkan dengan kerjasama dengan mitra-mitra yang lebih berpengalaman. Di dalam supervisi, petugas profesional pada umumnya belajar dengan bantuan orang yang lebih berpengalaman, atau di daerah tertentu dimana supervisi terhadap rekan kerja lebih bersifat mendidik. Blount, A. J., \& Mullen, P. R. (2015) mengadaptasikan pandangan Vygotsky yang mengaplikasikan pandangan terapetik pada situasi supervisi. Dapat dikakan bahwa supervisor dapat menciptakan suatu zona perkembangan proximal melalui:

1. Menginterpretasikan situasi supervisi sebagai seting pemecahan masalah bersama (a joint problem solving setting) dimana pekerja dan supervisor mengejar suatu tujuan bersama;

2. Supervisor perlu meyakinkan supervisee sedemikian rupa bahwa dia percaya terhadap sikap kelenturan (plasticity) supervisi-nya sebagai seorang profesional;

3. Supervisor perlu memperkenalkan perkakas psikologis (seperti refleksi) untuk membantu supervises menguasai proses-proses intra psikologis (intra psychological proseses).

Jika bercermin pada aturan yang ditetapkan oleh Asosiasi Organisasi Nasional untuk Supervisi di Eropa para supervisor harus tamatan dari pendidikan pasca sarjana. Mereka dapat datang dari profesi yang berbeda, sebab supervisi meliputi profesi lapangan dan aliran yang berbeda. Artinya bahwa para supervisor adalah tenaga ahli yang terdidik dalam supervisi. Mereka mempunyai pengetahuan teoretis dan praktis dari lapangan supervisi dan di dalam pekerjaan supervisi mereka, mereka menggunakan metoda supervisi spesifik seperti refleksi (ZI orga, 1997). Mereka tidaklah perlu ahli dalam lapangan yang sama dengan keahlian tenaga profesional yang diawasinya (sekalipun sangat disarankan sama).

\section{E. SIMPULAN REKOMENDASI}

DAN

Dari studi analisis tentang Model Supervisi Perkembangan-Kependidikan (MSPK) maka dapat dirumuskan sebuah pandangan dan temuan baru bawha dewasa ini para supervisor di Eropa kebanyakan adalah psikolog, ahli mendidik, pekerja sosial dan baru-baru ini juga menyertakan para guru dan juga melibatkan para profesional yang mempunyai pengetahuan dan pengalaman pekerjaan dalam dinamika kelompok atau dalam psikoterapi.

Beberapa studi yang mengkaji pengalaman dan persepsi para peserta model supervisi pengembangan kependidikan telah dilakukan oleh para ahli (seperti Dekleva, 1996; Dekleva\& RapusÏ Pavel,1995; Kobolt, 1998; ZÏ orga, 1997a; ZÏ orga et al., 2001). Hasilnya menunjukkan bahwa di dalam proses supervisi, para tenaga profesional dalam lapangan sosial; psikolog, konselorsekolah, pekerja sosial dan para profesional lain dalam lapangan kepedulian sosial, mempunyai kesempatan untuk merefleksikan caracara bekerja mereka dan studi ini juga mengkaji perasaan mereka, reaksi, sikap dan harapan atas dasar situasi kerja mereka secara konkret. Mereka menerima dukungan dari rekan kerja 
mereka, bertukar pengalaman dan merefleksikan permasalahan dari perspektif yang berbeda-beda. Melalui model ini mereka belajar tentang diri mereka dan cara mereka berfungsi, bisa merasakan situasi kerja dari titik pandang yang lain, meningkatkan komunikasi mereka dan memperluas kompetensi professional mereka.

\section{DAFTAR PUSTAKA}

Abbott, A. A., \& Lyter, S. C. (1999). The use of constructive criticism in field supervision. The Clinical Supervisor, 17 (2), 43-57 doi: 10.1300/J001v17n0202.

Amerikaner, M., \& Rose, T. (2012). Direct observation of psychology supervisees' clinical work: A snapshot of current practice. The Clinical Supervisor, 31(1), 61-80.

Atherton, J.S. (1986). Professional Supervision In Group Care. London:

Tavistock.Bernard, J. M., \& Goodyear, R. K. (2014). Fundamentals of clinical supervision $\left(5^{\text {th }}\right.$ ed.). Columbus, $\mathrm{OH}$ : Pearson.

Blount, A. J., \& Mullen, P. R. (2015). Development of the integrative wellness model: Supervising counselors-in-training. The Professional Counselor, 5, 100-113. doi:10.15241/ajb.5.1.100.

Cobia, D. C., \& Boes, S. R. (2000). Professional disclosure statements and formal plansfor supervision: Two strategies for minimizing the risk of ethical conflicts in postmaster's supervision. Journal of Counseling and Development, 78, 293-296.

Dekleva, B. (1996). Supervision For Developmental Projects-Its Understanding, Practical Implementation and Future Needs).
Horizons Of Psychology, 5(2), 75-86.

Ellis, M. V. (2010). Bridging the science and practice of clinical supervision: Some discoveries, some misconceptions. The Clinical Supervisor, 29(1), 95116.

Holloway, E. (1995). Clinical Supervision: A Systems Approach. London: Sage.

Kadushin, A. (1976). Supervision In Social Work. New York: Columbia University Press.

Kolb, D.A. (1984). Experiential Learning. Experience As The Source Of Learning and Development. Englewood Cliffs, NJ: PrenticeHall.

Laireiter, A., \& Willutzki, W. (2003). Self-reflection and self-practice in training of cognitive behavioural therapy: an overview. Clinical Psychology and Psychotherapy, 10, 19-30.

Lawson, G., Hein, S.F., \& Stuart, C.L. (2009). A qualitative investigation of supervisee's experiences of triadic supervision. Journal of Counseling and Development, 87, 449-457.

Lerner, R.M. (1998). Theories Of Human Development: Contemporary Perspectives. In: W. Damon \& R.M. Lerner (Eds), Theoretical Models Of Human Development (Pp. 1-24). NewYork: JohnWiley\&Sons.

Merriam, S.B. \& Clark, M.C. (1992). Adult Learning In Good Times And Bad. Studies In Continuing Education, 14(1), 1-13.

Shulman, L. S. (2004). The wisdom of practice: Essays on teaching, 
learning, and learning to teach. San Francisco, CA: Jossey-Bass.

Skovholt, T. M., \& Rønnestad, M. H. (1992). Struggles of the novice counsellor and therapist. Journal of Counseling \& Development, 70, 505-515.

Sutton, L., Townend, M., \& Wright, J. (2007). The Experiences of Reflective Learning. Journals by cognitive-behavioural psychotherapy students. Reflective Practice, 8, 387-404.

Taufiq A. dkk. (2015). Model Penjaminan Pencapaian Kompetensi Profesional Calon Konselor melalui Supervisi Komprehensif (Laporan Penelitian Pascasrjana UPI), Bandung: Tidak Diterbitkan.

Thwaites, R. \& Bennett-Levy, J. (2007). Making the implicit explicit: Conceptualising empathy in cognitive behaviour therapy. Behavioural and Cognitive Psychotherapy, 35, 591-612.

Vygotsky, L.S. (1977). Development Of The Psychotherapy Supervisor. Psychotherapy, 27, 553-560.

Watkins, C.E. Jr. (1995). Researching Psychotherapy Supervisor Development: Four Key Considerations. The Clinical Supervisor, 13(2), 111-119.

Zï Orga, S. (1997). Professionals As Partners In Their Own Professional Development. 33rd IAAP International Conference On Developing Human Relations And Ethnic Understanding (Pp. 134143). Hardwar: Gurukul Kangri University. . (2001). Supervision Process Seen As A Process Of Experiential Learning. The Clinical Supervisor, 16(1), 145-161. 